\title{
SGLT2 inhibitors in T2D and associated comorbidities - differentiating within the class
}

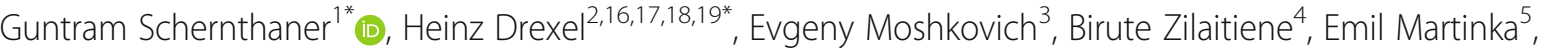 \\ Leszek Czupryniak ${ }^{6}$, Tamás Várkonyi ${ }^{7}$, Andrej Janež ${ }^{8}$, Kristine Ducena $^{9}$, Katarina Lalić ${ }^{10}$, Tsvetalina Tankova ${ }^{11}$, \\ Martin Prázný ${ }^{12}$, Lea Smirčić Duvnjak ${ }^{13}$, Olga Sukhareva ${ }^{14}$ and Harald Sourij ${ }^{15}$
}

\begin{abstract}
Background: For patients with type 2 diabetes (T2D), cardiovascular disease (CVD) is the single most common cause of mortality. In 2008 and 2012, the Federal Drug Administration (FDA) and the European Medicines Agency (EMA) respectively mandated cardiovascular outcomes trials (CVOTs) on all new anti-diabetic agents, as prospective trials statistically powered to rule out excess cardiovascular risk in patients with T2D. Unexpectedly, some of these CVOTs have demonstrated not only cardiovascular safety, but also cardioprotective effects, as was first shown for the SGLT2 inhibitor empagliflozin in EMPA-REG OUTCOME.

Expert opinion: To debate newly available CVOT data and to put them into context, we convened as a group of medical experts from the Central and Eastern European Region. Here we describe our discussions, focusing on the conclusions we can draw from EMPA-REG OUTCOME and other SGLT2 inhibitor CVOTs, including when considered alongside real-world evidence.
\end{abstract}

Conclusion: CVOTs investigating SGLT2 inhibitors have suggested benefits beyond glucose lowering that have been confirmed in real-world evidence studies.

Keywords: Type 2 diabetes, SGLT2 inhibitor, Empagliflozin, Canagliflozin, Dapagliflozin, Cardiovascular disease

\section{Background}

The majority of people worldwide who are living with diabetes are affected by type 2 diabetes (T2D) $[1,2]$ and, among these individuals, more than $50 \%$ of mortality is due to cardiovascular (CV) causes [3]. Estimates of 6 or 12 fewer years of life for a typical 60-year old male with T2D or with T2D and CV disease (CVD) have been given when compared with counterparts in the nondiabetic population [4]. Furthermore, the presence of T2D confers a 2- to 5-fold higher risk of developing heart failure (HF) and a $60-80 \%$ greater probability of death from $\mathrm{CV}$ causes in those who have established $\mathrm{HF}$ [5-8]. As with CVD, kidney disease is a strong predictor of mortality in people with T2D [9], and up to $40 \%$ of

\footnotetext{
* Correspondence: guntram.schernthaner@meduniwien.ac.at; heinz.drexel@extern.insel.ch

${ }^{1}$ Department of Medicine I, Rudolfstitung Hospital, Vienna, Austria

${ }^{2}$ VIVIT-Institute, Academic Teaching Hospital Feldkirch, Feldkirch, Austria

Full list of author information is available at the end of the article
}

people with T2D will eventually develop kidney failure [10]. Both low estimated glomerular filtration rate (eGFR) and high urine albumin-to-creatinine ratio (UACR) are independent predictors of CV death [11]. Thus, the morbidity and mortality burdens presented by $\mathrm{CV}$ and renal complications of T2D are considerable.

Although lifestyle interventions are a key first step in managing the care of people with T2D, the majority of patients will eventually need medication [12]. Before the late 1950s, when biguanides were introduced, only insulin and sulfonylureas were available, but from the 1980s onwards metformin quickly became the glucose-lowering drug of choice for people with T2D [13]. Indeed, unless a specific contraindication such as severe renal or liver disease is present, metformin remains the first-line drug for the treatment of people with T2D [13]. Although three new classes of T2D agents were introduced in the 1990s $(\alpha$-glucosidase inhibitors, meglitinides and thiazolidinediones), it

(c) The Author(s). 2019 Open Access This article is distributed under the terms of the Creative Commons Attribution 4.0 International License (http://creativecommons.org/licenses/by/4.0/), which permits unrestricted use, distribution, and reproduction in any medium, provided you give appropriate credit to the original author(s) and the source, provide a link to the Creative Commons license, and indicate if changes were made. The Creative Commons Public Domain Dedication waiver (http://creativecommons.org/publicdomain/zero/1.0/) applies to the data made available in this article, unless otherwise stated. 
was not until the turn of the Twenty-First Century that the so-called "newer T2D agents" were introduced: dipeptidyl peptidase-4 (DPP-4) inhibitors, glucagon-like peptide-1 (GLP-1) receptor agonists and sodium-glucose transporter 2 (SGLT2) inhibitors [13].

In recent years, the Federal Drug Administration (FDA) has mandated $\mathrm{CV}$ outcomes trials (CVOTs) to assess the CV safety of all new glucose-lowering drugs, while the European Medicines Agency (EMA) has recommended either a CVOT or a meta-analysis $[14,15]$. Unexpectedly, the results reported for treatment with the SGLT2 inhibitor empagliflozin in the EMPA-REG OUTCOME CVOT showed, for the first time, that an anti-diabetic agent could not only deliver glucoselowering efficacy without any additional CV risk, but could actually provide CV benefit [16]. This benefit included a reduction in $\mathrm{CV}$ death in the study population, which also contributed to a reduced risk of death by any cause [16]. Subsequent CVOTs have also revealed $\mathrm{CV}$ benefits for a small number of other glucoselowering drugs, whereas others did not show any $\mathrm{CV}$ benefits [16-26]. Among CV benefits, only SGLT2 inhibitors have suggested a decrease in hospitalisation for heart failure [6, 16-18].

With the new CVOT results, a paradigm for antidiabetic drugs is emerging in which glucose-lowering is only one element of the overall treatment aim. As CV risk is the aspect of T2D that leads to the greatest mortality [3], we believe that CV health is an important consideration when deciding on the most appropriate therapies for any one individual. An integrated approach to disease management is desirable, encompassing prevention or control of $\mathrm{CV}$ risk together with the avoidance of renal complications, as these two factors are inextricably linked [27]. Furthermore, drug dosing can be challenging for patients who develop chronic kidney disease (CKD), as impaired kidney function can potentially influence the pharmacokinetics of every therapeutic agent, and through different mechanisms [28]. Given that many glucoselowering drugs have not yet been extensively tested in a CKD population, making detailed analyses of renal data in the CVOT studies could be especially important, although dedicated renal studies are also ongoing.

At the American Diabetes Association (ADA) annual congress in June 2017, several new sets of data were presented from studies of SGLT2 inhibitors, including the main results from the CANVAS Program on canagliflozin and the CVD-REAL real-world evidence (RWE) study encompassing empagliflozin, canagliflozin and dapagliflozin $[17,29]$. As a group of experts in the field from the Central and Eastern European Region, we subsequently met to discuss the significance of the results and to put them into context for practitioners treating people with T2D. We here report the resultant discussions on how best to interpret EMPA-REG OUTCOME, the CANVAS Program and RWE in order to inform clinical practice. During the preparation of this manuscript, important disclosures were made regarding the results of DECLARE-TIMI 58 (a CVOT on dapagliflozin) and regarding early results of the EMPRISE realworld evidence study on empagliflozin [18, 30]; owing to their importance for understanding the broader picture of SGLT2 inhibitor CVOTs, these new disclosures are also briefly discussed.

\section{Expert opinion \\ SGLT2 inhibitors}

SGLT2 inhibitors partially block the reabsorption of glucose in the proximal tubules in the kidney [31]. The members of this class have somewhat similar molecular structure but nevertheless possess differing relative selectivity for SGLT2 compared with SGLT1 [32]. Until recently, three SGLT2 inhibitors had been approved by the EMA and FDA for the treatment of T2D, as an adjunct to diet and exercise: canagliflozin (approval: EMA/FDA 2013); dapagliflozin (approval: EMA 2012/ FDA 2014); and empagliflozin (approval: EMA/FDA 2014). Of these three, empagliflozin shows the highest relative selectivity, being more than 2500-fold more selective for SGLT2 than SGLT1, followed by dapagliflozin at $>1100$-fold, and canagliflozin at $>250$-fold [32]. Such factors may be pertinent when discussing relative efficacies and safety profiles of these molecules, although the clinical relevance is unknown.

At the present time, CVOTs have been reported for empagliflozin (EMPA-REG OUTCOME), canagliflozin (the CANVAS Program) and dapagliflozin (DECLARETIMI 58) (Table 1). An additional SGLT2 inhibitor, ertugliflozin, was approved by the EMA and FDA in 2018 and 2017, respectively; however, results have not yet been reported for the ongoing ertugliflozin CVOT (VERTIS-CV) (Table 1).

\section{EMPA-REG OUTCOME}

The EMPA-REG OUTCOME CVOT investigated empagliflozin in addition to standard of care in a population of 7200 adult patients with both T2D and established CVD at baseline, defined as one or more of previous myocardial infarction (MI), stroke or unstable angina; multivessel coronary artery disease (CAD); single-vessel CAD if in addition to positive stress ischaemia test or recent hospitalisation for unstable angina; or occlusive peripheral artery disease (PAD) [16]. As the study drug or placebo was added to standard of care, patients in all study arms were well treated for dyslipidaemia and hypertension [16].

The primary composite outcome was time to first occurrence of 3-point major adverse CV event (3P-MACE; 
Table 1 Overview of SGLT2 inhibitor CVOTs

\begin{tabular}{|c|c|c|c|c|}
\hline Study & Trial \# & Completion & Primary outcome(s) & Main reported secondary CV and renal outcomes \\
\hline $\begin{array}{l}\text { EMPA-REG } \\
\text { OUTCOME } \\
\text { (empagliflozin) } \\
{[16,33]}\end{array}$ & NCT01131676 & $\begin{array}{l}\text { Completed } \\
\text { 2015; results } \\
\text { published }\end{array}$ & $\begin{array}{l}\text { Time to first } \\
\text { Occurrence of 3P- } \\
\text { MACE }\end{array}$ & $\begin{array}{l}\text { 4P-MACE; CV death; death by any cause; symptomatic Ml; } \\
\text { symptomatic non-fatal Ml; silent Ml; hospitalisation for unstable an- } \\
\text { gina; coronary revascularisation procedure; stroke; non-fatal stroke; } \\
\text { TIA; HHF; HHF or CV death excluding stroke; incident or worsening } \\
\text { nephropathy or CV death; incident or worsening nephropathy; pro- } \\
\text { gression to macroalbuminuria; dSCr and eGFR } \leq 45 \mathrm{ml} / \mathrm{min} / 1.73 \mathrm{~m}^{2} \text {; } \\
\text { initiation of RRT; dSCr and eGFR } \leq 45 \mathrm{ml} / \mathrm{min} / 1.73 \mathrm{~m}^{2} \text {, initiation of } \\
\text { RRT or renal death; incident albuminuria in patients with normal al- } \\
\text { bumin at baseline }\end{array}$ \\
\hline
\end{tabular}

$\begin{array}{llll}\text { CANVAS } & \text { NCT01032629 (CANVAS) } & \text { Completed } & \text { Time to first } \\ \text { Program } & \text { \& NCT01989754 } & \text { 2017; results } & \text { Occurrence of 3P- } \\ \text { (canagliflozin) } & \text { (CANVAS-R) } & \text { published } & \text { MACE }\end{array}$

$[17,34]$
Death by any cause; CV death; progression of albuminuria; CV death or HHF; non-fatal Ml; non-fatal stroke; Ml; stroke; hospitalisation for any cause; HHF; new-onset albuminuria; new-onset microalbuminuria; new-onset macroalbuminuria; $\mathrm{dSCr}$, ESRD or renal death; $\mathrm{dSCr}$, ESRD, renal death or new-onset macroalbuminuria; dSCr, ESRD, renal death or CV death; $\geq 40 \%$ decrease in $\mathrm{GFR}, \mathrm{ESRD}$ or renal death; $\geq 40 \%$ decrease in eGFR, ESRD, renal death or newonset macroalbuminuria; $\geq 40 \%$ decrease in eGFR, ESRD, renal death or CV death; $40 \%$ reduction in eGFR; dSCr; ESRD; ESRD or renal death

$\geq 40 \%$ decrease in eGFR to eGFR $<60 \mathrm{ml} / \mathrm{min} / 1.73 \mathrm{~m}^{2}$, ESRD, renal death or $\mathrm{CV}$ death; death by any cause; $\geq 40 \%$ decrease in eGFR to eGFR $<60 \mathrm{ml} / \mathrm{min} / 1.73 \mathrm{~m}^{2}$, ESRD or renal death; HHF; Ml; ischaemic stroke; CV death; non-CV death

MACE

Time to first occurrence of $\mathrm{CV}$ death or HHF

(dapagliflozin)

$\begin{array}{llll}\text { VERTIS-CV } & \text { NCT01986881 } & \text { Estimated } & \text { Time to first } \\ \text { (ertugliflozin) } & & \text { completion } & \text { Occurrence of 3P- } \\ \text { [35] } & 2019 & \text { MACE }\end{array}$

Results not yet reported

Definitions differed between trials. 3P-MACE is a composite of CV death, MI and stroke. 4P-MACE is a composite of CV death, MI, stroke and hospitalisation for unstable angina. Study names: EMPA-REG OUTCOME [cardiovascular outcomes trial of empagliflozin]; CANVAS, Canagliflozin Cardiovascular Assessment Study; CANVAS-R, Study of the Effects of Canagliflozin on Renal Endpoints in Adult Subjects with T2DM; DECLARE-TIMI, Multicenter Trial to Evaluate the Effect of Dapagliflozin on the Incidence of Cardiovascular Events; VERTIS-CV Randomized, Double-Blind, Placebo-Controlled, Parallel-Group Study to Assess Cardiovascular Outcomes Following Treatment With Ertugliflozin (MK-8835/PF-04971729) in Subjects With Type 2 Diabetes Mellitus and Established Vascular Disease. 3/4P-MACE, 3/4-point major adverse CV event; CV, cardiovascular; dSCr, doubling of serum creatinine; eGFR, estimated glomerular filtration rate; ESRD, end-stage renal disease; HHF, hospitalisation for heart failure; MI, myocardial infarction; RRT, renal replacement therapy; TIA, transient ischaemic attack

that is, CV death, non-fatal stroke or non-fatal myocardial infarction). Although EMPA-REG OUTCOME was only designed to test non-inferiority for this outcome, the study unexpectedly also demonstrated superiority, with a relative risk reduction (RRR) of 14\%, primarily driven by a $38 \%$ reduction in CV death [16]. Thus, key outcomes in EMPA-REG OUTCOME were significantly improved when empagliflozin was added to standard of care (Table 2).

Several secondary CV outcomes also showed reductions, including hospitalisation for $\mathrm{HF}$ (HHF) by $35 \%$ [16]. Death by any cause showed a $32 \%$ reduction, and the number needed to treat (NNT) to prevent one death over three years of the study was calculated as 39 [16]. However, no significant differences to placebo were seen for non-fatal stroke or non-fatal MI [16].

\section{Empagliflozin in subjects at increased CV risk}

It is important to consider which individuals with T2D will benefit from empagliflozin, although, in our opinion, it might be more appropriate simply to exclude those who would not benefit, as empagliflozin is currently somewhat unique in its safety and efficacy profile. We believe that empagliflozin is increasingly perceived as fulfilling a dual role of treating both hyperglycaemia and $\mathrm{CV}$ risk factors and is therefore suitable for patients with both T2D and CVD; indeed, this has now been recognised in updated product labels and international guidelines [36-41]. Although the EMPA-REG OUTCOME study included patients with established CVD, a metaanalysis of eight randomised controlled trials (RCTs) of empagliflozin analysed data from 11,292 subjects, including those at low and medium, as well as high, risk of CV events [42]. The primary endpoint was a composite of CV death, non-fatal MI, non-fatal stroke and hospitalisation for unstable angina (4P-MACE), and there was a secondary endpoint of 3P-MACE [42]. 4P-MACE occurred in 365 (9.5\%) patients receiving placebo and 635 (8.5\%) patients receiving empagliflozin (HR 0.86; 95\% CI 0.76-0.98). 3P-MACE occurred in 307 (8.0\%) patients receiving placebo and $522(7.0 \%)$ patients receiving empagliflozin (HR 0.84; 95\% CI 0.73-0.96) [42]. It can be inferred from these data that empagliflozin remains associated with a reduced risk of CV morbidity and mortality in patients with T2D, even when those at low/ medium CV risk are included in the analysed population. 
Table 2 Key efficacy outcomes in SGLT2 inhibitor CVOTS

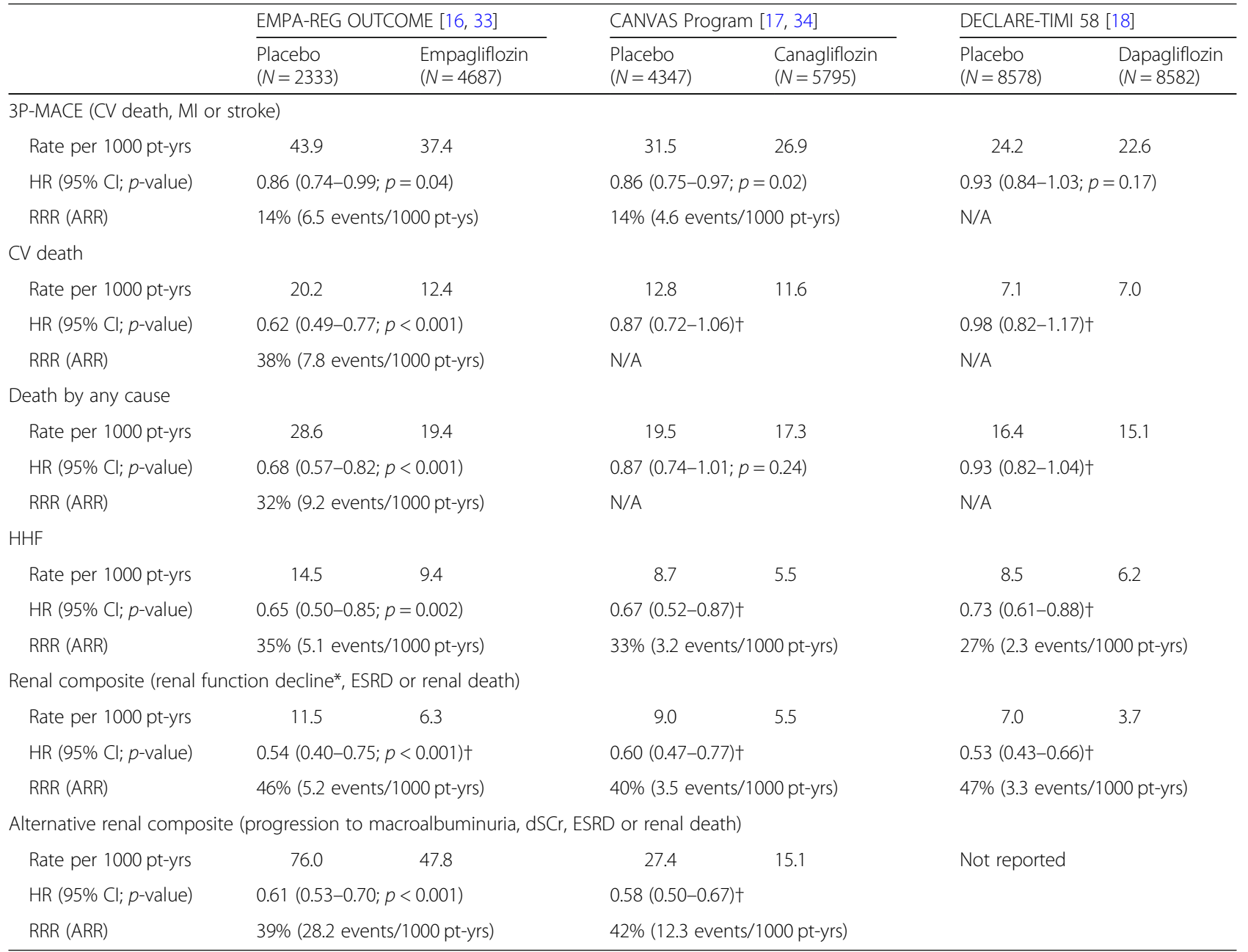

Please note that direct comparison of trials may not be accurate owing to differences in study design, populations and methodology. RRR and ARR are only shown where a significant reduction was reported, or a nominally significant reduction in the case of an exploratory analysis. *Defined as: dSCr accompanied by eGFR of $<45 \mathrm{ml} / \mathrm{min} / 1.73 \mathrm{~m}^{2}$ in EMPA-REG OUTCOME; $\leq 40 \%$ decrease in eGFR in the CANVAS Program; and $\leq 40 \%$ decrease in eGFR to $<60 \mathrm{ml} / \mathrm{min} / 1.73 \mathrm{~m}{ }^{2}$ in DECLARE-TIMI 58. +Exploratory analysis, $p$-value is nominal or not available. 3P-MACE, 3-point major adverse CV event; ARR, absolute risk reduction; Cl, confidence interval; $\mathrm{CV}$, cardiovascular; $\mathrm{dSCr}$, doubling of serum creatinine; $\mathrm{HHF}$, hospitalisation for heart failure; $\mathrm{HR}$, hazard ratio; $\mathrm{Ml}$, myocardial infarction; pt-yrs, patientyears; RRR, relative risk reduction

An analysis of HHF outcomes (a prespecified secondary endpoint) in EMPA-REG OUTCOME showed that the benefits of empagliflozin were consistent in subjects both with and without baseline HF, i.e. primary prevention in those with no HF at baseline and secondary prevention in those for whom HF had been reported at baseline. The analysis showed that $1.8 \%$ of patients receiving empagliflozin without HF at baseline experienced an event compared with $3.1 \%$ for placebo (HR 0.6; 95\% CI 0.43-0.82); for patients with baseline HF, the HHF figures were 10.4 and $12.3 \%$, respectively (HR 0.75 ; $95 \%$ CI $0.48-1.19$ ) [16, 43]. The evidence for primary prevention of HF with empagliflozin has now been recognised by new American Heart Association (AHA) and American
College of Cardiology (ACC) guidelines [40], and ongoing clinical studies are seeking to shed more light on this potential benefit; however, it should be noted that empagliflozin is not currently indicated for the treatment of HF.

Reductions in CV death were similar in patients with and without $\mathrm{HF}$ at baseline: $\mathrm{CV}$ death events occurred in $3.2 \%$ of subjects treated with empagliflozin vs $5.3 \%$ with placebo (HR $0.60 ; 95 \%$ CI $0.47-$ 0.77 ) for no baseline $\mathrm{HF}$, and $8.2 \%$ vs $11.1 \%$ (HR 0.71 ; 95\% CI 0.43-1.16) for subjects with baseline HF [43]. We note that EMPRISE will examine CV death outcomes in a broad $\mathrm{CV}$ risk population in routine clinical practice, but these data have not yet been reported [30]. 


\section{Renal outcomes in EMPA-REG OUTCOME}

The population of EMPA-REG OUTCOME included a substantial renal burden, with eGFR $<60 \mathrm{~mL} / \mathrm{min} /$ $1.73 \mathrm{~m}^{2}$ in $26 \%$ of patients and $60-<90 \mathrm{~mL} / \mathrm{min} / 1.73 \mathrm{~m}^{2}$ in $52 \%$ of patients $[16,33]$. The main pre-specified renal composite outcome of new or worsening nephropathy (progression to macroalbuminuria, doubling of the serum creatinine level, initiation of renal-replacement therapy, or death from renal disease) was significantly reduced by $39 \%$, and doubling of serum creatinine with an eGFR $\leq 45 \mathrm{~mL} / \mathrm{min} / 1.73 \mathrm{~m}^{2}$ was reduced by $44 \%$ when adding empagliflozin to standard of care [16, 33].

Significant benefits were also seen in several other prespecified renal parameters, including a $32 \%$ RRR in new or worsening nephropathy or CV death $(p<0.001)$; $38 \%$ RRR in progression to macroalbuminuria $(p<0.001)$; and $55 \%$ RRR in initiation of renal replacement therapy $(p=0.04)$ [33]. The only exception was incident albuminuria in patients with a normal albumin level at baseline, where no significant difference between study arms was observed [33].

The renal results in EMPA-REG OUTCOME indicate that empagliflozin delays the progression of renal disease when compared with placebo [33]. The change in eGFR over time also supports a nephroprotective effect: after an initial fall when empagliflozin therapy was started, the eGFR of subjects on empagliflozin recovered somewhat and subsequently remained stable, whereas those on placebo demonstrated a steady decline over the period of the study [33]. Furthermore, a post hoc analysis showed that the renal benefits seen with empagliflozin in the full study cohort were consistent in a subgroup of patients with prevalent kidney disease at baseline, defined as having an eGFR $<60 \mathrm{~mL} / \mathrm{min} / 1.73 \mathrm{~m}^{2}$ and/or macroalbuminuria (UACR $>300 \mathrm{mg} / \mathrm{g}$ ) [44].

Despite the promising renal results, it should be noted that EMPA-REG OUTCOME was a CV trial with 3PMACE as the primary endpoint, and therefore we await the results of an ongoing dedicated renal study before making a more conclusive assessment of empagliflozin in this setting. Furthermore, in accordance with local prescribing information and licences for SGLT2 inhibitors, if the eGFR is below $60 \mathrm{~mL} / \mathrm{min} / 1.73 \mathrm{~m}^{2}$ then empagliflozin should not be initiated and must be discontinued if the eGFR persistently falls below $45 \mathrm{ml} /$ $\min / 1.73 \mathrm{~m}^{2}$ [36].

\section{Key safety data in EMPA-REG OUTCOME}

Of note, the only adverse event for which an increased incidence was associated with empagliflozin in EMPAREG OUTCOME was the occurrence of genital infections (overall, $6.4 \%$ vs $1.8 \% ; p<0.001$ ), and these are easily treatable [16]. In contrast to the recent data from the CANVAS Program (see below; Table 3), [17] there was no significant increase with empagliflozin on the risk of bone fracture or lower limb amputation [16, 45], including in patients with PAD [47].

\section{The CANVAS Program}

The CANVAS Program is a pooled analysis of two subsidiary studies: CANVAS, a CV safety study, and CANVAS-Renal (CANVAS-R), which included

Table 3 Key safety outcomes in SGLT2 inhibitor CVOTS

\begin{tabular}{|c|c|c|c|c|c|c|c|c|c|c|}
\hline & \multicolumn{3}{|c|}{ EMPA-REG OUTCOME $[45,46]^{*}$} & \multicolumn{3}{|c|}{ CANVAS $[17,46]$} & \multicolumn{2}{|c|}{ CANVAS-R $[17,46]$} & \multicolumn{2}{|c|}{$\begin{array}{l}\text { DECLARE-TIMI 58† } \\
{[18,46]}\end{array}$} \\
\hline & $\begin{array}{l}\text { Placebo } \\
(N=2333)\end{array}$ & $\begin{array}{l}\text { Empa } 10 \\
(N=2345)\end{array}$ & $\begin{array}{l}\text { Empa } 25 \\
(N=2342)\end{array}$ & $\begin{array}{l}\text { Placebo } \\
(N=1441)\end{array}$ & $\begin{array}{l}\text { Cana } 100 \\
(N=1445)\end{array}$ & $\begin{array}{l}\text { Cana } 300 \\
(N=1441)\end{array}$ & $\begin{array}{l}\text { Placebo } \\
(N=2903)\end{array}$ & $\begin{array}{l}\text { Cana } 100 \\
(N=2904)\end{array}$ & $\begin{array}{l}\text { Placebo } \\
(N=8569)\end{array}$ & $\begin{array}{l}\text { Dapagliflozin } \\
(N=8574)\end{array}$ \\
\hline \multicolumn{11}{|c|}{ Patients with lower limb amputation } \\
\hline n (\%) & $43(1.8)$ & $42(1.8)$ & $46(2.0)$ & $22(1.5)$ & $50(3.5)$ & $45(3.1)$ & $25(0.9)$ & $45(1.5)$ & $113(1.3)$ & $123(1.4)$ \\
\hline $\begin{array}{l}\text { Events per } 1000 \\
\text { patient-years }\end{array}$ & 6.5 & 6.2 & 6.8 & 2.8 & 6.2 & 5.5 & 4.2 & 7.5 & 3.3 & 3.6 \\
\hline Hazard ratio $(95 \% \mathrm{Cl})$ & - & $\begin{array}{l}0.96 \\
(0.63-1.47)\end{array}$ & $\begin{array}{l}1.04 \\
(0.69-1.58)\end{array}$ & - & $\begin{array}{l}2.24 \\
(1.36-3.69)\end{array}$ & $\begin{array}{l}2.01 \\
(1.20-3.34)\end{array}$ & - & $\begin{array}{l}1.80 \\
(1.10-2.93)\end{array}$ & - & $\begin{array}{l}1.09 \\
(0.84-1.40)\end{array}$ \\
\hline \multicolumn{11}{|l|}{ Diabetic ketoacidosis } \\
\hline & $\begin{array}{l}\text { Placebo } \\
(N=2333)\end{array}$ & \multicolumn{2}{|c|}{$\begin{array}{l}\text { Empagliflozin (pooled) } \\
(N=4687)\end{array}$} & \multicolumn{3}{|c|}{$\begin{array}{l}\text { Placebo (pooled } \neq) \\
(N=4347)\end{array}$} & \multicolumn{2}{|c|}{$\begin{array}{l}\text { Canagliflozin (pooled } \neq) \\
(N=5795)\end{array}$} & $\begin{array}{l}\text { Placebo } \\
(N=8569)\end{array}$ & $\begin{array}{l}\text { Dapagliflozin } \\
(N=8574)\end{array}$ \\
\hline n (\%) & $1(<0.1 \%)$ & \multicolumn{2}{|l|}{$4(0.1 \%)$} & \multicolumn{3}{|l|}{6} & \multicolumn{2}{|l|}{12} & 12 & 27 \\
\hline $\begin{array}{l}\text { Events per } 1000 \\
\text { patient-years }\end{array}$ & $<0.1$ & \multicolumn{2}{|l|}{0.1} & \multicolumn{3}{|l|}{0.3} & \multicolumn{2}{|l|}{0.6} & 0.4 & 0.9 \\
\hline Hazard ratio $(95 \% \mathrm{Cl})$ & - & \multicolumn{2}{|c|}{$1.99(0.22-17.80)$} & \multicolumn{3}{|l|}{-} & \multicolumn{2}{|c|}{$2.33(1.10-7.17)$} & - & $\begin{array}{l}2.18 \\
(1.10-4.30)\end{array}$ \\
\hline
\end{tabular}

These trials cannot be directly compared, owing to differences in study design, populations and methodology. *Post hoc analysis for lower limb amputation, which was not a prespecified outcome in EMPA-REG OUTCOME. †All amputation; data for lower limb amputation not provided. $¥$ Diabetic ketoacidosis events pooled across CANVAS and CANVAS-R, and $100 \mathrm{mg}$ and $300 \mathrm{mg}$ doses of canagliflozin. Pooled cohort size indicates the intention to treat population. Cana 100/ 300, canagliflozin 100/300 mg; Empa 10/25, empagliflozin 10/25 mg 
albuminuria progression as a key outcome alongside CV safety outcomes [17].

\section{The CANVAS Program study design}

The CANVAS CVOT was a randomised controlled trial designed to assess the $\mathrm{CV}$ safety of canagliflozin versus placebo, on top of standard of care in 4330 patients with T2D and either symptomatic CVD (one or more of $\mathrm{CAD}$, cerebrovascular disease or PAD) or multiple $\mathrm{CV}$ risk factors (age $\geq 50$ and two or more of dyslipidaemia, hypertension, current smoker, $\geq 10$ years diabetes duration, or albuminuria) at baseline [17]. A public disclosure of interim analyses was required for regulatory filings, and plans to further assess $\mathrm{CV}$ protection through an expansion of the study were terminated at that time $[17,48,49]$. Instead, in order to achieve sufficient power for $\mathrm{CV}$ assessment, the additional CANVAS-R CVOT $(N=5813)$ was combined with CANVAS into the CANVAS Program, enabling a pooled analysis, but excluding events accrued prior to 20 November 2012, which was the date of last unblinding $[17,48,49]$. CANVAS-R was a shorter study, with median follow-up 2.1 years [17].

Statistical analyses were performed as a sequential hypothesis testing plan of the pooled data from CANVAS and CANVAS-R to give a total of 5795 individuals treated with canagliflozin and 4347 placebo controls [17]. As with EMPA-REG OUTCOME, the primary endpoint in the CANVAS Program was time to first occurrence of 3P-MACE (first testing for non-inferiority and then superiority) [17]. Next was a test for superiority for death by any cause, followed by superiority for $\mathrm{CV}$ death [17]. Once a non-significant result was encountered, subsequent analyses were exploratory only.

\section{Key outcomes in the CANVAS Program}

The primary analysis yielded a positive result, with 26.9 participants receiving canagliflozin experiencing an event per 1000 patient-years compared with 31.5 in the placebo group (HR 0.86; 95\% CI 0.75-0.97, $p=0.02$ for superiority); however, superiority was not shown for the first secondary outcome (death by any cause, HR 0.87 95\% CI $0.74-1.01$ ), so the sequential hypothesis testing ended there [17]. This means that the results of all subsequent secondary analyses could not be considered as significant but rather as exploratory analyses (Table 2) [17].

It should be noted here that superiority for death by any cause and $\mathrm{CV}$ death were additions made by the independent trial steering committee for the CANVAS Program when revising the original analysis plan $[48,49]$. These revisions were made in the expectation that the results for individual mortality outcomes would be stronger than for the composite outcome of 3P-MACE, as had been seen in EMPA-REG OUTCOME [48, 49]. Adding CV death as an outcome also presented an opportunity to demonstrate superiority in an individual CV outcome $[48,49]$. However, the lack of superiority for all-cause mortality in the pooled data means that the subsequent analysis of $\mathrm{CV}$ death was exploratory only [17]. Similarly, subsequent analysis of CANVAS-R data alone, including superiority for albuminuria progression, composite of HHF and $\mathrm{CV}$ death, and CV death, also remain exploratory only [17].

\section{Canagliflozin in subjects at increased $\mathrm{CV}$ risk}

The significant 3P-MACE finding echoes that in EMPAREG OUTCOME for empagliflozin; however, the lack of significance for both CV death and death by any cause was disappointing from a clinical point of view, as these parameters may be of most interest to clinicians, given the prevalent CV risk in patients with T2D [17].

The CANVAS Program study populations comprised $58.9 \%$ of patients with symptomatic CVD in CANVAS and $70.7 \%$ in CANVAS-R; the pooled figure was $65.6 \%$ [17]. These figures for $\mathrm{CV}$ involvement are more heterogeneous than the EMPA-REG OUTCOME population, where $99 \%$ of participants had established CVD [16]. Analysis of risk groups has shown that canagliflozin was superior to placebo for 3P-MACE in the secondary prevention group only, with no difference from placebo when looking only at primary prevention $[46,50]$. However, when analysed for interactions between the primary, secondary and overall population, no statistically significant difference was seen $(p=0.18)$ [50].

The 35\% of CANVAS Program patients who had CV risk factors but not symptomatic disease represent a challenge when interpreting the results, as the absence of symptoms does not necessarily represent an absence of disease, as evidenced by studies showing that people with T2D are known to have a high burden of asymptomatic CVD and that CAD may manifest in a silent fashion [51].

\section{Renal outcomes in the CANVAS program}

Analyses of renal outcomes in the CANVAS Program were exploratory only, owing to the failure to meet previous endpoints in the statistical hierarchy [17]. Nevertheless, exploratory findings with canagliflozin were promising, suggesting reductions not only in albuminuria, which we believe may not be the most robust metric for assessing effect on kidney function, but also in doubling of serum creatinine, which is a key marker of impaired renal function [34]. These suggested benefits are consistent with renal observations with empagliflozin treatment in EMPA-REG OUTCOME [33]. Renal burden in the CANVAS Program population was also reminiscent of EMPA-REG OUTCOME, with eGFR $<60$ 
$\mathrm{mL} / \mathrm{min} / 1.73 \mathrm{~m}^{2}$ in $20 \%$ of patients and $60-<90 \mathrm{~mL} /$ $\mathrm{min} / 1.73 \mathrm{~m}^{2}$ in $55 \%$ of patients [52].

\section{Key safety data from the CANVAS program}

The safety results of note from the CANVAS Program showed an approximate two-fold increased risk of lower limb amputations with canagliflozin versus placebo (6.3 vs. 3.4 participants with amputation per 1000 patientyears: HR 1.97; 95\% CI 1.41-2.75, $p<0.001$ ) (Table 3), and confirmed a previous suggested increase in bone fractures (15.4 vs 11.9 participants with fracture per 1000 patient-years; HR, 1.26 ; $95 \%$ CI 1.04 to $1.52, p=$ 0.02) [17]. The only other event of significance in the CANVAS Program was an increase in genital infections in both men and women $(p<0.001)$, most likely due to the increased levels of glucose in the urine, and also seen with other SGLT2 inhibitors [17].

The incidence of lower limb amputation with canagliflozin was not uniform across all groups: patients with atherosclerosis and previous amputation had a higher risk of amputation compared with other patients [17]. Although amputations of the toe and middle of the foot were the most common, amputations involving the leg, below and above the knee, also occurred and some patients had more than one amputation, some involving both limbs [17].

In February 2017, the EMA issued a statement requiring a warning of the potential increased risk of toe amputation in the prescribing information for all SGLT2 inhibitors based on canagliflozin data, including from the CANVAS Program; however, the statement noted that an increased risk has not been seen to date in studies with empagliflozin or dapagliflozin [53]. Indeed, although amputation was not a pre-specified safety outcome of EMPA-REG OUTCOME, a post hoc analysis found no increased signal for amputation with empagliflozin compared with placebo [45]. Both the EMA and FDA have required the addition of a warning for increased risk of lower limb amputation to the canagliflozin label, but not to the empagliflozin or dapagliflozin labels [54].

The mechanisms by which canagliflozin may increase the risk of amputation are still unclear [54], especially as, we suggest, there does not appear to be a similar signal from empagliflozin or dapagliflozin. We believe that the increase in amputation rate is concerning, as the potential repercussions on quality of life are profound. It can be argued that many, if given the choice, would opt to accept an increased $\mathrm{CV}$ risk over a doubled risk of amputation.

\section{DECLARE-TIMI 58}

The first results for the DECLARE-TIMI 58 CVOT on dapagliflozin have now been reported, enabling a more comprehensive analysis of $\mathrm{CV}$ and renal outcomes across the SGLT2 inhibitor class [18]. Although the data were disclosed subsequent to our initial discussions, and during the preparation of this manuscript, we believe that it is important to briefly address the findings here.

Notably, DECLARE-TIMI 58 is the first CVOT in the SGLT2 inhibitor class to include a majority of primary prevention patients; that is, $59 \%$ of patients had multiple $\mathrm{CV}$ risk factors (male aged $\geq 55$ or female aged $\geq 60$ with one or more of dyslipidaemia; hypertension; or current smoker), whereas only $41 \%$ of patients had established atherosclerotic CVD (age $\geq 40$ with one or more of CAD; ischaemic cerebrovascular disease; or PAD) $[18,55]$.

In the initial study design, the primary safety endpoint was non-inferiority for 3P-MACE and the primary efficacy endpoint was superiority for 3P-MACE, as with EMPA-REG OUTCOME and the CANVAS Program. However, following EMPA-REG OUTCOME, a new coprimary composite efficacy endpoint of $\mathrm{HHF}$ and $\mathrm{CV}$ death was added, with permission from regulators, in light of the new insights that these outcomes may be highly clinically relevant with SGLT2 inhibitors [16, 18, 56].

As expected, DECLARE-TIMI 58 demonstrated that dapagliflozin was non-inferior to placebo as an add-on to standard of care in the study population, thus meeting the primary safety endpoint [18]. Similarly, DECLARETIMI 58 added further evidence that a reduction in HHF is consistent across the SGLT2 inhibitor class, as the co-primary efficacy endpoint of HHF or CV death was also met, and this was driven entirely by a decreased risk of HHF, while there was no difference between dapagliflozin and placebo in risk of CV death [18].

However, the study failed to meet the primary efficacy endpoint of superiority for 3P-MACE, with no significant difference between dapagliflozin and placebo [18]. Furthermore, even when looking only at patients with baseline established atherosclerotic CVD (a similar size cohort to EMPA-REG OUTCOME), there remained no significant benefit in either 3P-MACE or CV death with dapagliflozin $[18,46]$. The risk of death by any cause was also not significantly reduced with dapagliflozin vs placebo [18].

\section{Considering EMPA-REG OUTCOME alongside the CANVAS Program and DECLARE-TIMI 58}

Although direct comparisons can only be made between the effects of different agents in head-to-head studies, owing to differences in populations, trial designs, analytical approaches and drug effects, it can nevertheless be useful for clinicians to critically appraise data in the context of similar studies.

In a clinical setting, we believe that $\mathrm{CV}$ death could be considered to be the most relevant parameter for assessing the overall benefit from a glucose-lowering drug for 
patients with T2D, as reductions in CV death are the prime goal of treatment. In the EMPA-REG OUTCOME study, the RRR of CV death for empagliflozin vs placebo was $38 \%$ (HR 0.62; 95\% CI 0.49-0.77, $p<0.001$ ) [16]. By contrast, as described above, the RRR of CV death did not achieve statistical significance in either the CANVAS Program or in DECLARE-TIMI 58 [17, 18]. Thus, reduction in CV death was, among SGLT2 inhibitors, a unique finding with empagliflozin.

The results for HHF and renal outcomes were more similar between the three CVOTs. Whereas HHF is only presented as an exploratory outcome in the CANVAS Program (HR 0.67; 95\% CI 0.52-0.87) and DECLARETIMI 58 (HR 0.73; 95\% CI 0.61-0.88), the observed trend towards treatment benefit is similar to that seen with empagliflozin in EMPA-REG OUTCOME, where RRR for HHF was 35\% (HR 0.65; 95\% CI 0.50-0.85, $p<0.001)$ [16-18].

The design of composite renal outcomes differed between studies, and there is not a composite renal endpoint that has been reported for all three CVOTs. For the CANVAS Program, the key renal composite was a $40 \%$ reduction in eGFR, requirement for renal replacement therapy, or death from renal causes [17], while in DECLARE-TIMI 58 the composite comprised $40 \%$ reduction in eGFR to $<60 \mathrm{ml} / \mathrm{min} / 1.73 \mathrm{~m}^{2}$, end-stage renal disease, or death from renal causes [18]. Due to the failure to meet earlier endpoints, these renal outcomes were exploratory only in the two trials, but nevertheless both suggested a strong trend towards a protective effect with treatment, with $40 \%$ reduction in the CANVAS Program (HR 0.60; 95\% CI 0.47-0.77) and $47 \%$ reduction in DECLARE-TIMI 58 (HR 0.53; 95\% CI $0.43-0.66)$.

There was no equivalent pre-specified endpoint in EMPA-REG OUTCOME, although a post hoc analysis of doubling of serum creatinine accompanied by an eGFR of $<45 \mathrm{ml} / \mathrm{min} / 1.73 \mathrm{~m}^{2}$, initiation of renal replacement therapy, or death due to renal disease is the closest approximate, and showed a similar benefit to the other CVOTs (46\% reduction; HR 0.54; 95\% CI 0.40-0.75) (Table 2) [33]. As noted above, results for the EMPAREG OUTCOME prespecified composite of incident or worsening nephropathy, which also included progression to macroalbuminuria, were also similar (HR 0.61; 95\% CI $0.53-0.70, p<0.001)[16,33]$. An equivalent composite in the CANVAS Program yielded similar results in an exploratory analysis (HR 0.58; 95\% CI 0.50-0.67) [34]. Albuminuria outcomes have not yet been reported for DECLARE-TIMI 58 [18].

In safety outcomes, much attention has been paid to the doubling of lower limb amputations in the CANVAS Program, in contrast to DECLARE-TIMI 58 and EMPAREG OUTCOME, where no signal was seen (Table 3)
$[17,18,45]$. Thus, canagliflozin is to date the only SGLT2 inhibitor that has produced a CVOT signal for lower limb amputation risk.

Bone fracture risk was also increased in the CANVAS Program but not EMPA-REG OUTCOME or DECLARETIMI 58, whereas the rare event of diabetic ketoacidosis (DKA) was significantly increased in DECLARE-TIMI 58 and had a trend towards an increase that did not reach significance in the CANVAS Program and EMPA-REG OUTCOME (Table 3) [16-18]. The prescribing information for all SGLT2 inhibitors cautions prescribers to be alert for signs of DKA, which although rare is potentially dangerous and may present atypically (that is, in patients with only moderately increased blood glucose values) [36].

There was a mixed picture for urogenital infections in SGLT2 inhibitor CVOTs. While there was a consistent signal for increased risk of genital infections with all three agents, which was also seen in previous trials [16-18], none of the CVOTs showed an increase risk of urinary tract infection (UTI), although a signal was seen with empagliflozin when looking at female patients alone [16]. Other studies have shown inconsistent results for UTI risk with SGLT2 inhibitors, with four recent meta-analyses finding no evidence for increased risk of UTI with any agent in the class, with the possible exception of high dose (10 mg) dapagliflozin [57-60]. Nevertheless, prescribers should be advised that current product labels contain a warning about possible UTI events [36].

To summarise the SGLT2 CVOT data, despite the recent CANVAS Program and DECLARE-TIMI 58 results, empagliflozin remains the only member of the SGLT2 inhibitor class thus far having proven a significant reduction in $\mathrm{CV}$ death (38\% RRR) in a dedicated and robust CVOT that was designed, and powered, to test for superiority in $\mathrm{CV}$ outcomes versus placebo [16-18]. Furthermore, the reduced risk of CV death with empagliflozin was consistent across prespecified analyses [16]. By contrast, there was no significant reduction in CV death versus placebo with either canagliflozin, in the CANVAS Program, or dapagliflozin, in DECLARE-TIMI 58, and this was true whether analysing each study population as a whole or only the patients with baseline symptomatic atherosclerotic CVD $[17,18,46,50]$. However, HHF and renal endpoints suggested that all SGLT2 inhibitors provided a benefit for these outcomes, although these analyses were exploratory only in the CANVAS Program and DECLARETIMI 58 due to the hierarchical statistical testing plan design [16-18, 33, 34]. Safety outcomes also showed differences, with increased risk of lower limb amputation and bone fracture in the CANVAS Program, but not EMPA-REG OUTCOME or DECLARE-TIMI 58, although an increased risk of genital infections was consistent across the class, and prescribers should be 
advised of the possibility of rare DKA events with all three agents [16-18, 36, 45].

One possible explanation for different outcomes between SGLT2 inhibitor CVOTs may be differences in study design, some of which are outlined above. However, another explanation may be the differences in molecular structure that result in different relative selectivity for SGLT2 over SGLT1 [32]. SGLT1 inhibition is known to cause gastrointestinal problems and investigations into the earliest SGLT2 inhibitors were abandoned owing to their lack of selectivity between SGLT1 and SGLT2 [61]. It may be that there are other repercussions of the different molecular structures that have not yet been identified.

\section{Real-world evidence}

In recent years, RWE has begun to provide insights into clinical and health economic outcomes with SGLT2 inhibitors in routine clinical practice, and ongoing RWE studies are set to shed still further light on this in the years to come. RWE is captured in natural, uncontrolled settings outside of traditional RCTs, and has been said to "represent a measure in understanding healthcare data collected under real-life practice circumstances" [62]. RWE studies can provide data on effectiveness and safety during routine care, complement and support data from RCTs, and support market access and reimbursement decisions [62]. However, RWE alone is insufficient to demonstrate efficacy, and thus cannot be used on its own to meet regulatory requirements for passing a new indication or extending an existing indication [63]. RWE is commonly used for patient profiling and prevalence, defining treatment pathways and patterns of care, evaluating compliance and persistence, determining treatment costs and costs in disease stages and disease states, and informing investigations on health outcomes and disease sequelae [62].

\section{CVD-REAL}

CVD-REAL was a RWE study that compared the rate of HHF in individuals with T2D who had been newly initiated on SGLT2 inhibitors (canagliflozin, dapagliflozin or empagliflozin) versus other glucose-lowering drugs (oGLDs), with secondary aims of comparing the risk of all-cause death, and HHF or all-cause death, between the two treatment groups [29]. The cohort included both patients with and without established CVD at baseline [29]. For patients without CVD at baseline, HF may be a key outcome, as it was shown to be among the most common first presentations of CVD in a prospective cohort study of health records over 5.5 years $(14.1 \%$ of patients with T2D) [64].

Data for CVD-REAL were gathered from registries and national initiatives from six different countries (US,
UK and Nordic countries). From an initial postscreening population of 160,033 people who had been prescribed an SGLT2 inhibitor and 1,226,221 who had been given an oGLD, subjects were propensity matched 1:1 to give a test population of 154,528 for each of SGLT2 inhibitors or oGLDs [29]. This propensity matching step ensured that the baseline characteristics were similar for each group, although they did differ somewhat from CVOTs: for example, patients were relatively young (57 years vs 63-64 years in CVOTs); fewer (13\%) had prior CVD; statin use was relatively high at $67 \%$, but slightly less than in CVOTs; and concomitant GLP-1 receptor agonists were much more widely used (18-20\% in CVD-REAL vs $3-5 \%$ in SGLT2 inhibitor CVOTs) [16-18, 29]. Overall, $53 \%$ of the study population received canagliflozin, 37\% received dapagliflozin and 10\% received empagliflozin. These percentages varied by region: in the US, $75.9 \%$ received canagliflozin, whereas in Europe $91.9 \%$ received dapagliflozin. All three primary analyses favoured SGLT2 inhibitors over oGLD: HHF (HR 0.61; 95\% CI 0.51-0.73, $p<0.001$ ); death by any cause (HR 0.49; 95\% CI 0.41-0.57, $p<0.001$ ), and a composite of HHF or death by any cause (HR 0.54; $95 \%$ CI $0.48-0.60, p<0.001$ ) [29]. Results for individual SGLT2 inhibitors were not reported.

The related study CVD-REAL 2 used a similar study design to look at $\mathrm{CV}$ and mortality outcomes in realworld data from an additional six countries (four from Asia Pacific, plus Canada and Israel), with 235,000 treatment initiations in each study arm [65]. In this second study, $75 \%$ of patients received dapagliflozin, with the remainder split between empagliflozin (9\%), canagliflozin (4\%), and three additional SGLT2 inhibitors that are not currently licensed in the European Union (12\%) [65]. Results in CVD-REAL 2 were similar to CVD-REAL, with a lower incidence of the composite of HHF or death by any cause (HR 0.60; 95\% CI 0.47-0.76, $p<0.001$ ), as well as a lower incidence of the individual components HHF (HR 0.64; 95\% CI $0.50-0.82, p=0.001$ ) and death by any cause (HR 0.51; 95\% CI 0.37-0.70, $p<0.001$ ) [65].

\section{EASEL}

The EASEL study was a retrospective cohort study of SGLT2 inhibitors in patients with T2D and CVD that used data from the US Department of Defense (DoD) Military Health System (MHS) [66]. The study found that patients newly initiated on SGLT2 inhibitors had $43 \%$ fewer HHF or death by any cause events than propensity matched patients initiated on non-SGLT2 inhibitor therapy (1.73 versus 3.01 composite events per 100 person-years; HR, 0.57; 95\% CI, 0.50-0.65) [66]. Similarly, the number of MACE events was 33\% lower in the SGLT2 inhibitor cohort than in the propensity matched non-SGLT2 inhibitor cohort (2.31 versus 3.45 events per 
100 person-years; HR, 0.67; 95\% CI, 0.60-0.75). However, pooled safety data showed that SGLT2 inhibitors were associated with an approximately 2-fold higher risk of below knee lower extremity amputation, similar to the risk observed with canagliflozin in the CANVAS Program [17, 66]. The amputation rates for the individual agents varied slightly, with canagliflozin showing a slightly higher incidence rate than empagliflozin or dapagliflozin, after propensity matching [66].

\section{EMPRISE}

During the preparation of this manuscript, early results from an additional RWE study were announced. The study, EMPRISE, uses 3 large US databases to assess outcomes with empagliflozin in routine clinical practice, with DPP-4 inhibitors as an active comparator [30]. EMPRISE will assess a range of effectiveness, safety, healthcare resource utilisation and cost outcomes, in a patient population with a much broader CV risk than in EMPA-REG OUTCOME [30]. By the time of study completion, it is envisaged that 232,000 patients will have been included over the course of 5 years, with 116,000 patients in each propensity matched arm [30]. Recently, initial effectiveness results after 5 months follow-up were disclosed for selected outcomes in the first 35,000 patients [30]. These results suggested that patients receiving empagliflozin had substantially fewer HHF events than patients receiving DPP-4 inhibitors (HR 0.49; 95\% CI 0.27-0.89) [30]. Thus, preliminary results from EMPRISE are reminiscent of the rapid benefit seen with empagliflozin in reducing HHF events in the controlled conditions of EMPA-REG OUTCOME $[16,43]$.

\section{RWE data in context}

We believe that the value of RWE must be cautiously taken in the context of evidence from CVOTs, as data generated from observational studies are not comparable to gold standard RCTs, and residual confounding such as selection bias cannot be excluded. For example, no information is available on the safety profile of SGLT2 inhibitors within CVD-REAL, nor on CV risk, making it difficult to draw conclusions regarding risk:benefit profiles. Of particular note, the reductions in all-cause mortality reported with pooled SGLT2 inhibitors in CVD-REAL were not replicated for canagliflozin in the CANVAS Program, nor for dapagliflozin in DECLARE-TIMI 58 [17, 18, 29]. Indeed, there is a possible inherent bias in the CVD-REAL design, due to the hierarchical nature of therapy for T2D, in which patients are generally prescribed SGLT2 inhibitors only after therapy with oGLD. This means that for such patients the oGLD treatment period becomes defined as "immortal", as patients who are subsequently prescribed SGLT2 inhibitors, by definition, have survived $[29,67]$. However, we note that the authors of the study have argued against the potential of such a bias to affect the results [68], and as such the subject remains a matter of debate [69]. Concerns over the possibility of immortal time bias have been addressed in the study design for EMPRISE, where patients are matched for number of diabetes therapies and the study is designed to compare treatments with the same position in the treatment pathway [30].

It is our opinion that RWE studies can be of use where the data support and agree with results from RCTs. For example, the evidence from RWE supports the findings from CVOTs showing a reduction in HHF with SGLT2 inhibitors, which suggests that the reduction in HHF demonstrated in CVOTs may be observed in T2D patients across a broad continuum of CVD in routine clinical practice.

\section{SGLT2 inhibitors and class effect - what is the evidence from CVOTs and RWE?}

Taking into consideration the various results from SGLT2 inhibitor CVOTs, we consider that it is still too early to safely assume a class effect. As such, we believe that each agent should be evaluated according to its individual data and merit.

In particular, we feel that the different results in $\mathrm{CV}$ death, death by any cause and safety cast doubt on the potential extent of a class effect, despite similar reductions in HHF and renal outcomes (and exploratory findings) between the three CVOTs. We note that variability across a class in $\mathrm{CV}$ death outcomes has a clear precedent in CVOTs: among GLP-1 receptor agonist CVOTs, a reduction in CV death was seen with liraglutide, but not with lixisenatide, exenatide, semaglutide or the unlicensed agent albiglutide [23-26, 70].

International guidelines that have been updated in the light of CVOTs have recognised this distinction, recommending an SGLT2 inhibitor or GLP-1 receptor agonist with proven $\mathrm{CV}$ benefit for patients with T2D in an atherosclerotic CVD setting [37-39]; or an SGLT2 inhibitor with proven HF or CKD benefit in patients where HF or CKD predominates $[37,38]$.

\section{Conclusions}

CVOTs investigating SGLT2 inhibitors have suggested benefits beyond glucose lowering that have been confirmed in RWE studies [16-18, 29, 30, 33, 34, 65, 66], which has led guidelines to support a favourable positioning for these agents early in the treatment pathway for patients with T2D in the setting of CV risk, HF and renal disease [37-41]. However, empagliflozin is the only drug within this class to have demonstrated proven efficacy and safety across the most relevant endpoints, namely CV death and death by any cause, as well as other $\mathrm{CV}$ and renal outcomes [16-18]. 


\section{Abbreviations}

3/4P-MACE: 3/4-point MACE; ADA: American Diabetes Association; Cl: Confidence interval; CV: Cardiovascular; CVD: CV disease; CVOT: CV outcomes trial; eGFR: Estimated glomerular filtration rate; EMA: European Medicines Agency; FDA: US Food and Drug Administration; GLP-1: Glucagonlike peptide-1; HF: Heart failure; HHF: Hospitalisation for heart failure; HR: Hazard ratio; MACE: Major adverse CV event; oGLD: Other glucoselowering drug; PAD: Peripheral artery disease; RCT: Randomised controlled trial; RRR: Relative risk reduction; RWE: Real-world evidence; SGLT1/ 2: Sodium-glucose transporter 1/2; T1/2D: Type 1/2 diabetes; UACR: Urine albumin-to-creatinine ratio

\section{Acknowledgements}

Editorial support was provided by Fortis Pharma Consulting, with financial support from BI.

\section{Authors' contributions}

GS and HD led and moderated the initial discussions. GS, HD, EM1, BZ, EM2, $L C, T V, A J, K D, K L, T, M P, L S D, O S$ and HS participated in the interpretation of the data under discussion and were involved in drafting, and critical review of, the manuscript. All authors have given final approval of the version to be published.

\section{Funding}

Financial support for the preparation for this manuscript was provided by Boehringer Ingelheim (BI). The opinions expressed are entirely the authors' own and the only involvement of BI was to have sight of the manuscript for accuracy.

\section{Availability of data and materials}

Data sharing is not applicable to this article as no datasets were generated or analysed during the current study. All data discussed were taken from the published sources cited.

\section{Ethics approval and consent to participate}

Not applicable.

\section{Consent for publication}

Not applicable.

\section{Competing interests}

OS has previously received honoraria for speaking and consultancy from Boehringer Ingelheim, Astra-Zeneca, Johnson \& Johnson LLC, Merck, Sanofi, Takeda, Novartis, BMS. GS, HD, EM1, BZ, EM2, LC, TV, AJ, KD, KL, TT, MP, LSD and HS declare no competing interests.

\footnotetext{
Author details

${ }^{1}$ Department of Medicine I, Rudolfstitung Hospital, Vienna, Austria. ${ }^{2}$ VIVIT-Institute, Academic Teaching Hospital Feldkirch, Feldkirch, Austria ${ }^{3}$ Unit of Endocrinology and Metabolism, Sapir Medical Center, Kfar-Saba, Israel. ${ }^{4}$ Institute of Endocrinology, Lithuanian University of Health Sciences, Kaunas, Lithuania. ${ }^{5}$ National Institute of Endocrinology and Diabetology, Lubochna, Slovakia. ${ }^{6}$ Department of Diabetology and Internal Medicine, Warsaw Medical University, Warsaw, Poland. ${ }^{7} 1$ st Dept of Internal Medicine, University of Szeged, Szeged, Hungary. ${ }^{8}$ Department of Endocrinology, Diabetes and Metabolic Diseases, University Medical Centre, Ljubljana, Slovenia. ${ }^{9}$ Division of Endocrinology, Faculty of Internal Medicine, University of Latvia, Riga, Latvia. ${ }^{10}$ Clinic for Endocrinology, Diabetes and Metabolic Diseases, Clinical Centre of Serbia, Faculty of Medicine, University of Belgrade, Beograd, Serbia. ${ }^{11}$ Clinical Centre of Endocrinology, Medical University Sofia, Sofia, Bulgaria. ${ }^{12}$ Diabetes Centre, Charles University and General Faculty Hospital, Prague, Czech Republic. ${ }^{13}$ School of Medicine, University of Zagreb, Vuk Vrhovac University Clinic-UH Merkur, Zagreb, Croatia.

${ }^{14}$ Endocrinology Research Centre, Moscow, Russian Federation. ${ }^{15}$ Division of Endocrinology and Diabetology, Medical University of Graz, Graz, Austria.

${ }^{16}$ Vorarlberg Institute for Vascular Investigation and Treatment (VIVIT), Feldkirch, Austria. ${ }^{17}$ Division of Angiology, Swiss Cardiovascular Center, University Hospital of Berne, Bern, Switzerland. ${ }^{18}$ Private University of the Principality of Liechtenstein, Triesen, Liechtenstein. ${ }^{19}$ Drexel University College of Medicine, Philadelphia, PA, USA
}

Received: 12 October 2018 Accepted: 27 May 2019

Published online: 17 June 2019

\section{References}

1. Alberti KG, Zimmet PZ. Definition, diagnosis and classification of diabetes mellitus and its complications. Part 1: diagnosis and classification of diabetes mellitus provisional report of a WHO consultation. Diabet Med. 1998;15:539-53.

2. Global Report on Diabetes 2016. pp. 1-88: World Health Organization; 2016:1-88.

3. Nwaneri C, Cooper H, Bowen-Jones D. Mortality in type 2 diabetes mellitus: magnitude of the evidence from a systematic review and meta-analysis. British J Diabetes Vascular Dis. 2013:13:192-207.

4. The Emerging Risk Factors Collaboration. Association of cardiometabolic multimorbidity with mortality. JAMA. 2015;314:52-60.

5. Cubbon RM, Adams B, Rajwani A, Mercer BN, Patel PA, Gherardi G, Gale CP, Batin PD, Ajjan R, Kearney L, et al. Diabetes mellitus is associated with adverse prognosis in chronic heart failure of ischaemic and non-ischaemic aetiology. Diab Vasc Dis Res. 2013;10:330-6.

6. Gilbert RE, Krum H. Heart failure in diabetes: effects of anti-hyperglycaemic drug therapy. Lancet. 2015;385:2107-17.

7. Kannel WB, Hjortland M, Castelli WP. Role of diabetes in congestive heart failure: the Framingham study. Am J Cardiol. 1974;34:29-34.

8. MacDonald MR, Petrie MC, Varyani F, Ostergren J, Michelson EL, Young JB, Solomon SD, Granger CB, Swedberg K, Yusuf S, et al. Impact of diabetes on outcomes in patients with low and preserved ejection fraction heart failure: an analysis of the candesartan in heart failure: assessment of reduction in mortality and morbidity (CHARM) programme. Eur Heart J. 2008;29:1377-85.

9. Reidy K, Kang HM, Hostetter T, Susztak K. Molecular mechanisms of diabetic kidney disease. J Clin Invest. 2014;124:2333-40.

10. National Kidney Foundation. Diabetes - a major Risk factor for kidney disease. [https://www.kidney.org/atoz/content/diabetes]. Accessed June 2019.

11. Chronic Kidney Disease Prognosis C, Matsushita K, van der Velde M, Astor BC, Woodward M, Levey AS, de Jong PE, Coresh J, Gansevoort RT. Association of estimated glomerular filtration rate and albuminuria with allcause and cardiovascular mortality in general population cohorts: a collaborative meta-analysis. Lancet. 2010;375:2073-81.

12. National Institute for Health and Care Excellence. Type 2 diabetes in adults [https://www.nice.org.uk/guidance/ng28/ifp/chapter/medicines-to-controlblood-glucose]. Accessed June 2019.

13. Kirby MG. Sixty years of diabetes management in primary care. British J Diabetes Vascular Dis. 2013;12:315-20.

14. FDA: Guidance for Industry. Diabetes Mellitus - Evaluating Cardiovascular Risk in New Antidiabetic Therapies to Treat Type 2 Diabetes. 2008.

15. EMA: Reflection paper on assessment of cardiovascular risk of medicinal products for the treatment of cardiovascular and metabolic diseases. 2015.

16. Zinman B, Wanner C, Lachin JM, Fitchett D, Bluhmki E, Hantel S, Mattheus M, Devins T, Johansen OE, Woerle HJ, et al. Empagliflozin, cardiovascular outcomes, and mortality in type 2 diabetes. $N$ Engl J Med. 2015;373:2117-28.

17. Neal B, Perkovic V, Mahaffey KW, de Zeeuw D, Fulcher G, Erondu N, Shaw W, Law G, Desai M, Matthews DR, et al. Canagliflozin and cardiovascular and renal events in type 2 diabetes. N Engl J Med. 2017;377:644-57.

18. Wiviott SD, Raz I, Bonaca MP, Mosenzon O, Kato ET, Cahn A, Silverman MG, Zelniker TA, Kuder JF, Murphy SA, et al. Dapagliflozin and cardiovascular outcomes in type 2 diabetes. New Engl J Med. 2019;380:347-57.

19. Scirica BM, Bhatt DL, Braunwald E, Steg PG, Davidson J, Hirshberg B, Ohman P, Frederich R, Wiviott SD, Hoffman EB, et al. Saxagliptin and cardiovascular outcomes in patients with type 2 diabetes mellitus. N Engl J Med. 2013;369:1317-26.

20. White WB, Cannon CP, Heller SR, Nissen SE, Bergenstal RM, Bakris GL, Perez AT, Fleck PR, Mehta CR, Kupfer $\mathrm{S}$, et al. Alogliptin after acute coronary syndrome in patients with type 2 diabetes. N Engl J Med. 2013;369:1327-35.

21. Green JB, Bethel MA, Armstrong PW, Buse JB, Engel SS, Garg J, Josse R, Kaufman KD, Koglin J, Korn S, et al. Effect of sitagliptin on cardiovascular outcomes in type 2 diabetes. N Engl J Med. 2015;373:232-42.

22. Rosenstock J, Perkovic V, Johansen OE, Cooper ME, Kahn SE, Marx N, Alexander $\mathrm{JH}$, Pencina M, Toto RD, Wanner C, et al. Effect of linagliptin vs placebo on major cardiovascular events in adults with type 2 diabetes and high cardiovascular and renal risk: the CARMELINA randomized clinical trial. JAMA. 2019;321:69-79. 
23. Marso SP, Daniels GH, Brown-Frandsen K, Kristensen P, Mann JF, Nauck MA, Nissen SE, Pocock S, Poulter NR, Ravn LS, et al. Liraglutide and cardiovascular outcomes in type 2 diabetes. N Engl J Med. 2016;375:311-22.

24. Marso SP, Bain SC, Consoli A, Eliaschewitz FG, Jódar E, Leiter LA, Lingvay I, Rosenstock J, Seufert J, Warren ML, et al. Semaglutide and cardiovascular outcomes in patients with type 2 diabetes. N Engl J Med. 2016;375:1834-44.

25. Pfeffer MA, Claggett B, Diaz R, Dickstein K, Gerstein HC, Kober LV, Lawson FC, Ping $L$, Wei $X$, Lewis EF, et al. Lixisenatide in patients with type 2 diabetes and acute coronary syndrome. N Engl J Med. 2015;373:2247-57.

26. Holman RR, Bethel MA, Mentz RJ, Thompson VP, Lokhnygina Y, Buse JB, Chan JC, Choi J, Gustavson SM, lqbal N, et al. Effects of once-weekly exenatide on cardiovascular outcomes in type 2 diabetes. N Engl J Med. 2017:377:1228-39.

27. Ronco C, Haapio M, House AA, Anavekar N, Bellomo R. Cardiorenal syndrome. J Am Coll Cardiol. 2008;52:1527-39.

28. Arnouts P, Bolignano D, Nistor I, Bilo H, Gnudi L, Heaf J, van Biesen W. Glucoselowering drugs in patients with chronic kidney disease: a narrative review on pharmacokinetic properties. Nephrol Dial Transplant. 2014;29:1284-300.

29. Kosiborod M, Cavender MA, Fu AZ, Wilding JP, Khunti K, Holl RW, Norhammar A, Birkeland Kl, Jorgensen ME, Thuresson M, et al. Lower risk of heart failure and death in patients initiated on sodium-glucose cotransporter-2 inhibitors versus other glucose-lowering drugs: the CVDREAL study (comparative effectiveness of cardiovascular outcomes in new users of sodium-glucose cotransporter-2 inhibitors). Circulation. 2017;136:249-59.

30. Patorno E, Pawar A, Franklin J, Najafzadeh M, Déruaz-Luyet A, Brodovicz K, Sambevski S, Bessette LG, Santiago Ortiz AJ, Kulldorff M, Schneeweiss S. Empagliflozin and the Risk of Heart Failure Hospitalization in Routine Clinical Care: A First Analysis from the Empagliflozin Comparative Effectiveness and Safety (EMPRISE) Study. Circulation. 2019. https://doi.org/10.1161/ CIRCULATIONAHA.118.039177.

31. Gallo LA, Ward MS, Fotheringham AK, Zhuang A, Borg DJ, Flemming NB, Harvie BM, Kinneally TL, Yeh SM, McCarthy DA, et al. Once daily administration of the SGLT2 inhibitor, empagliflozin, attenuates markers of renal fibrosis without improving albuminuria in diabetic $\mathrm{db} / \mathrm{db}$ mice. Sci Rep. 2016;6:26428.

32. Grempler R, Thomas L, Eckhardt M, Himmelsbach F, Sauer A, Sharp DE, Bakker RA, Mark M, Klein T, Eickelmann P. Empagliflozin, a novel selective sodium glucose cotransporter-2 (SGLT-2) inhibitor: characterisation and comparison with other SGLT-2 inhibitors. Diabetes Obes Metab. 2012;14:83-90.

33. Wanner C, Inzucchi SE, Lachin JM, Fitchett D, von Eynatten M, Mattheus $M$, Johansen OE, Woerle HJ, Broedl UC, Zinman B. Empagliflozin and progression of kidney disease in type 2 diabetes. N Engl J Med. 2016;375:323-34.

34. Perkovic V, de Zeeuw D, Mahaffey KW, Fulcher G, Erondu N, Shaw W, Barrett TD, Weidner-Wells M, Deng H, Matthews DR, et al. Canagliflozin and renal outcomes in type 2 diabetes: results from the CANVAS program randomised clinical trials. Lancet Diabetes Endocrinol. 2018;6:691-704.

35. Cannon CP, McGuire DK, Pratley R, Dagogo-Jack S, Mancuso J, Huyck S, Charbonnel B, Shih WJ, Gallo S, Masiukiewicz U, et al. Design and baseline characteristics of the eValuation of ERTugliflozin efflcacy and safety CardioVascular outcomes trial (VERTIS-CV). Am Heart J. 2018;206:11-23.

36. EMA. Jardiance SmPC. https://www.ema.europa.eu/en/medicines/human/ EPAR/jardiance. Accessed June 2019.

37. Davies MJ, D'Alessio DA, Fradkin J, Kernan WN, Mathieu C, Mingrone G, Rossing P, Tsapas A, Wexler DJ, Buse JB. Management of hyperglycaemia in type 2 diabetes, 2018. A consensus report by the American Diabetes Association (ADA) and the European Association for the Study of diabetes (EASD). Diabetologia. 2018;61:2461-98.

38. American Diabetes Association. Standards of medical Care in Diabetes-2019. Diabetes Care. 2019;42(Suppl 1):S1-S186.

39. Das SR, Everett BM, Birtcher KK, Brown JM, Cefalu WT, Januzzi JL Jr, Kalyani RR, Kosiborod M, Magwire ML, Morris PB, et al. 2018 ACC expert consensus decision pathway on novel therapies for cardiovascular risk reduction in patients with type 2 diabetes and atherosclerotic cardiovascular disease: a report of the American College of Cardiology Task Force on Expert Consensus Decision Pathways. J Am Coll Cardiol. 2018;72:3200-23.

40. Arnett DK, Blumenthal RS, Albert MA, Buroker AB, Goldberger ZD, Hahn EJ, Himmelfarb CD, Khera A, Lloyd-Jones D, McEvoy JW, et al. 2019 ACC/AHA guideline on the primary prevention of cardiovascular disease: a report of the American College of Cardiology/American Heart Association Task Force on Clinical Practice Guidelines. J Am Coll Cardiol. 2019 https://doi.org/10.1016/j.jacc.2019.03.010.

41. Piepoli MF, Hoes AW, Agewall S, Albus C, Brotons C, Catapano AL, Cooney MT, Corra U, Cosyns B, Deaton C, et al. 2016 European guidelines on cardiovascular disease prevention in clinical practice: the sixth joint task force of the European Society of Cardiology and Other Societies on cardiovascular disease prevention in clinical practice (constituted by representatives of 10 societies and by invited experts) developed with the special contribution of the European Association for Cardiovascular Prevention \& rehabilitation (EACPR). Eur Heart J. 2016;37:2315-81.

42. Salsali A, Kim G, Woerle HJ, Broedl UC, Hantel S. Cardiovascular safety of empagliflozin in patients with type 2 diabetes: a meta-analysis of data from randomized placebo-controlled trials. Diabetes Obes Metab. 2016;18:1034-40.

43. Fitchett D, Zinman B, Wanner C, Lachin JM, Hantel S, Salsali A, Johansen OE, Woerle HJ, Broedl UC, Inzucchi SE. Heart failure outcomes with empagliflozin in patients with type 2 diabetes at high cardiovascular risk: results of the EMPA-REG OUTCOME trial. Eur Heart J. 2016;37:1526-34.

44. Wanner C, Lachin JM, Inzucchi SE, Fitchett D, Mattheus M, George J, Woerle $\mathrm{HJ}$, Broedl UC, von Eynatten M, Zinman B, et al. Empagliflozin and clinical outcomes in patients with type 2 diabetes mellitus, established cardiovascular disease, and chronic kidney disease. Circulation. 2018;137:119-29.

45. Inzucchi SE, lliev H, Pfarr E, Zinman B. Empagliflozin and assessment of lower-limb amputations in the EMPA-REG OUTCOME trial. Diabetes Care. 2018:41:e4-5.

46. Zelniker TA, Wiviott SD, Raz I, Im K, Goodrich EL, Bonaca MP, Mosenzon O, Kato ET, Cahn A, Furtado RHM, et al. SGLT2 inhibitors for primary and secondary prevention of cardiovascular and renal outcomes in type 2 diabetes: a systematic review and meta-analysis of cardiovascular outcome trials. Lancet. 2019;393:31-9.

47. Verma S, Mazer CD, Al-Omran M, Inzucchi SE, Fitchett D, Hehnke U, George JT, Zinman B. Cardiovascular outcomes and safety of empagliflozin in patients with type 2 diabetes mellitus and peripheral artery disease: a subanalysis of EMPA-REG OUTCOME. Circulation. 2018;137:405-7.

48. Neal B, Perkovic V, Matthews DR, Mahaffey KW, Fulcher G, Meininger G, Erondu N, Desai M, Shaw W, Vercruysse F, et al. Rationale, design and baseline characteristics of the CANagliflozin cardioVascular assessment study-renal (CANVAS-R): a randomized, placebo-controlled trial. Diabetes Obes Metab. 2017;19:387-93.

49. Neal B, Perkovic V, Mahaffey KW, Fulcher G, Erondu N, Desai M, Shaw W, Law G, Walton MK, Rosenthal N, et al. Optimizing the analysis strategy for the CANVAS program: a prespecified plan for the integrated analyses of the CANVAS and CANVAS-R trials. Diabetes Obes Metab. 2017;19:926-35.

50. Mahaffey KW, Neal B, Perkovic V, de Zeeuw D, Fulcher G, Erondu N, Shaw W, Fabbrini E, Sun T, Li Q, et al. Canagliflozin for primary and secondary prevention of cardiovascular events: results from the CANVAS program (canagliflozin cardiovascular assessment study). Circulation. 2018;137:323-34.

51. Schernthaner G, Lotan C, Baltadzhieva-Trendafilova E, Ceponis J, Clodi M, Ducena K, Goncalvesova E, Guja C, Honka M, Janež A, et al. Unrecognised cardiovascular disease in type 2 diabetes: is it time to act earlier? Cardiovasc Diabetol. 2018;17:145.

52. Neuen BL, Ohkuma T, Neal B, Matthews DR, de Zeeuw D, Mahaffey KW, Fulcher G, Desai M, Li Q, Deng H, et al. Cardiovascular and renal outcomes with canagliflozin according to baseline kidney function. Circulation. 2018; 138:1537-50.

53. EMA: SGLT2 inhibitors: information on potential risk of toe amputation to be included in prescribing information. EMA/118223/2017. 2017.

54. Matthews DR, Li Q, Perkovic V, Mahaffey KW, de Zeeuw D, Fulcher G, Desai M, Hiatt WR, Nehler M, Fabbrini E, et al. Effects of canagliflozin on amputation risk in type 2 diabetes: the CANVAS program. Diabetologia. 2019. https://doi.org/10.1007/s00125-019-4839-8.

55. Raz I, Mosenzon O, Bonaca MP, Cahn A, Kato ET, Silverman MG, Bhatt DL, Leiter LA, McGuire DK, Wilding JPH, et al. DECLARE-TIMI 58: participants' baseline characteristics. Diabetes Obes Metab. 2018;20:1102-10.

56. Wiviott SD, Raz I, Bonaca MP, Mosenzon O, Kato ET, Cahn A, Silverman MG, Bansilal S, Bhatt DL, Leiter $L A$, et al. The design and rationale for the dapagliflozin effect on cardiovascular events (DECLARE)-TIMI 58 trial. Am Heart J. 2018;200:83-9.

57. Li D, Wang T, Shen S, Fang Z, Dong Y, Tang H. Urinary tract and genital infections in patients with type 2 diabetes treated with sodium-glucose cotransporter 2 inhibitors: a meta-analysis of randomized controlled trials. Diabetes Obes Metab. 2017;19:348-55. 
58. Liu J, Li L, Li S, Jia P, Deng K, Chen W, Sun X. Effects of SGLT2 inhibitors on UTIs and genital infections in type 2 diabetes mellitus: a systematic review and meta-analysis. Sci Rep. 2017;7:2824.

59. Puckrin R, Saltiel MP, Reynier P, Azoulay L, Yu OHY, Filion KB. SGLT-2 inhibitors and the risk of infections: a systematic review and meta-analysis of randomized controlled trials. Acta Diabetol. 2018:55:503-14.

60. Donnan JR, Grandy CA, Chibrikov E, Aubrey-Bassler K, Johnston K, Swab M, Hache J, Curnew D, Nguyen H, et al. Dose response of sodium glucose cotransporter-2 inhibitors in relation to urinary tract infections: a systematic review and network meta-analysis of randomized controlled trials. CMAJ Open. 2018;6:E594-602.

61. Kalra S. Sodium glucose co-transporter-2 (SGLT2) inhibitors: a review of their basic and clinical pharmacology. Diabetes Therapy. 2014;5:355-66.

62. Annemans L, Aristides M, Kubin M. Real-life data: a growing need. ISPOR Connections. 2007;13. https://web.archive.org/web/20161027061510/http:// www.ispor.org/news/articles/oct07/rld.asp.

63. Khosla S, White R, Medina J, Ouwens M, Emmas C, Koder T, Male G, Leonard $\mathrm{S}$. Real world evidence (RWE) - a disruptive innovation or the quiet evolution of medical evidence generation? [version 2; referees: 1; approved]. F1000Res. 2018;7:111.

64. Shah AD, Langenberg C, Rapsomaniki E, Denaxas S, Pujades-Rodriguez M, Gale CP, Deanfield J, Smeeth L, Timmis A, Hemingway H. Type 2 diabetes and incidence of cardiovascular diseases: a cohort study in 1.9 million people. Lancet Diabetes Endocrinol. 2015;3:105-13.

65. Kosiborod M, Lam CSP, Kohsaka S, Kim DJ, Karasik A, Shaw J, Tangri N, Goh SY, Thuresson M, Chen $\mathrm{H}$, et al. Cardiovascular events associated with SGLT2 inhibitors versus other glucose-lowering drugs: the CVD-REAL 2 study. J Am Coll Cardiol. 2018;71:2628-39.

66. Udell JA, Yuan Z, Rush T, Sicignano NM, Galitz M, Rosenthal N. Cardiovascular outcomes and risks after initiation of a sodium glucose cotransporter 2 inhibitor: results from the EASEL population-based cohort study. Circulation. 2018;137:1450-9.

67. Suissa S. Lower risk of death with SGLT2 inhibitors in observational studies: real or bias? Diabetes Care. 2018;41:6-10.

68. Thuresson M, Cavender MA, Fu AZ, Wilding JP, Khunti K, Holl RW, Norhammar A, Birkeland Kl, Jørgensen ME, Wittbrodt E, et al. Comment on Suissa. Lower risk of death with SGLT2 inhibitors in observational studies: real or bias? Diabetes care 2018;41:6-10. Diabetes Care. 2018;41:e106-8.

69. Suissa S. Response to Comment on Suissa. Lower Risk of Death With SGLT2 Inhibitors in Observational Studies: Real or Bias? Diabetes Care. 2018;41:6-10 Diabetes Care 2018, 41:e109-e110.

70. Hernandez AF, Green JB, Janmohamed S, D'Agostino RB Sr, Granger CB, Jones NP, Leiter LA, Rosenberg AE, Sigmon KN, Somerville MC, et al. Albiglutide and cardiovascular outcomes in patients with type 2 diabetes and cardiovascular disease (harmony outcomes): a double-blind, randomised placebo-controlled trial. Lancet. 2018;392:1519-29.

\section{Publisher's Note}

Springer Nature remains neutral with regard to jurisdictional claims in published maps and institutional affiliations.

\section{Ready to submit your research? Choose BMC and benefit from}

- fast, convenient online submission

- thorough peer review by experienced researchers in your field

- rapid publication on acceptance

- support for research data, including large and complex data types

- gold Open Access which fosters wider collaboration and increased citations

- maximum visibility for your research: over $100 \mathrm{M}$ website views per year

At $\mathrm{BMC}$, research is always in progress.

Learn more biomedcentral.com/submissions 